\title{
CLINICAL AND MORPHOLOGICAL FEATURES OF THE OVARIAN BRENNER TUMOUR: CURRENT STATE OF THE PROBLEM
}

DOI: 10.36740/WLek202007121

\author{
Mykhailo S. Myroshnychenko ${ }^{1}$, Olena 0. Dyadyk ${ }^{2}$, Victor D. Urzhumov ${ }^{3}$, Nataliia V. Kapustnyk ${ }^{4}$, Iryna V. Borzenkova ${ }^{5}$, \\ Larisa I. Selivanova', Inna I. Torianyk ${ }^{6}$, Yuliia Ya. Fedulenkova' ${ }^{1}$, Iuliia M. Kalashnyk' ${ }^{1}$, Pavel V. Tkachenko ${ }^{5}$, \\ Varvara R. Hryhorenko ${ }^{7}$, Dmytro V. Molodan' ${ }^{1}$, Serhii S. Myroshnychenko ${ }^{8}$ \\ 'KHARKIV NATIONAL MEDICAL UNIVERSITY, KHARKIV, UKRAINE \\ 2SHUPYK NATIONAL MEDICAL ACADEMY OF POSTGRADUATE EDUCATION, KYIV, UKRAINE \\ ${ }^{3}$ MILITARY MEDICAL CLINICAL CENTRE OF THE NORTHERN REGION, KHARKIV, UKRAINE \\ 4PUBLIC NON-PROFIT ORGANIZATION OF THE KHARKIV DISTRICT COUNCIL "REGIONAL CLINICAL PERINATAL CENTRE», KHARKIV, UKRAINE \\ 5PUBLIC NON-PROFIT ORGANIZATION OF THE KHARKIV DISTRICT COUNCIL «REGIONAL CLINICAL HOSPITAL», KHARKIV, UKRAINE \\ ${ }^{6}$ STATE INSTITUTION «INSTITUTE OF MICROBIOLOGY AND IMMUNOLOGY NAMED BY I.I. MECHNIKOV NATIONAL ACADEMY OF MEDICAL SCIENCES \\ OF UKRAINE», KHARKIV, UKRAINE \\ 7PUBLIC NON-PROFIT ORGANIZATION OF THE KHARKIV DISTRICT COUNCIL «KHARKIV REGIONAL CLINICAL CENTER OF UROLOGY AND NEPHROLOGY \\ NAMED AFTER V.I. SHAPOVAL", KHARKIV, UKRAINE \\ 8PUBLIC NON-PROFIT ORGANIZATION OF THE IZIUM CITY COUNCIL «CENTRAL CITY HOSPITAL OF SANDY MOTHER OF GOD», IZIUM, UKRAINE
}

\begin{abstract}
Introduction: Ovarian tumours are an actual problem of present-day medicine, being one of the most difficult sections of modern oncology. The majority of ovarian tumours are of epithelial origin. The ovarian Brenner tumour represents a rare epithelial ovarian neoplasm and accounts for 1-2\% of all ovarian neoplasms.

The aim of the study is to identify clinical and morphological features of ovarian Brenner tumour.

Materials and methods: The material was 5 cases of Brenner ovarian tumour, diagnosed in the study of 4 cases of operational material and 1 case of autopsy observation for the period from 2007 to 2019. Histological and immunohistochemical staining methods were used. The microspecimens were examined on an 0lympus BX-41 microscope (Japan). Results: Ovarian Brenner tumour is a rather rare pathology, the histogenesis of which is debatable. Morphological examination is the main method for its diagnosing. Ovarian Brenner tumours developed in women of middle and old age (the average age was 51.8 years). Women with a malignant ovarian Brenner tumour were older than women with a benign variant (the average age in women with a malignant variant was 55.8 years, with a benign variant -49.3 years). Benign ovarian Brenner tumour occurred more frequently compared with a malignant one. Malignant and benign variants of ovarian Brenner tumour were characterized by a one-sided nature of the lesion with frequent involvement in the pathological process of the left ovary. Clinically, in patients with a benign variant of the Brenner tumour in all cases an abdominal pain syndrome was determined, combined in one case with metrorrhagia. A malignant ovarian Brenner tumour was clinically manifested by severe abdominal pain syndrome, combined in one case with complaints of an increase in the size of the abdomen, and in another case with intoxication syndrome and a clinic of small bowel obstruction. In all cases a malignant ovarian Brenner tumour metastasized to the omentum and in one case also to the small intestine wall.

Macroscopically the ovarian Brenner tumour had the form of a node, the dimensions of which were significantly larger for the malignant variant compared with a benign, dense or soft consistency, on the cross section of a whitish-gray or brown color with cysts. A damaged ovary with a malignant variant of Brenner tumour significantly increased in size, while with a benign one, its size did not change or increased slightly. In all cases the malignant and benign variants of ovarian Brenner tumour were combined with various reproductive system organs pathologies (mucinous papillary cystadenoma of the ovary, serous ovarian cyst, ovarian endometriosis, endometrial hyperplasia, cervical nabothian cysts, uterine leiomyoma).

Conclusions: A study conducted by the authors revealed clinical and morphological features of a rare ovarian tumour - Brenner tumour, which will contribute to a better understanding of this pathology by the doctors of various specialties, and improve the treatment and diagnostic process.
\end{abstract}

KEY WORDS: ovarian Brenner tumour, morphology, clinical features

Wiad Lek. 2020;73(7):1420-1426

\section{INTRODUCTION}

Ovarian tumours are an actual problem of present-day medicine, being one of the most difficult sections of modern oncology [1]. Ovarian tumours exhibit a wide variation in structure and behaviour. There are numerous types of ovari- an tumours, and over all they fall into benign, borderline, or atypical proliferative and malignant categories. Benign ovarian tumours may occur at any point in life but they are most common during child bearing age and constitute about $90 \%$ of all ovarian tumours. These occur mostly in young women 
between the ages of 20 to 45 years, borderline tumours occur at slightly older ages. Malignant tumours are more common in older women, between the ages of 45 and 65 years [2].

Malignant tumours of the ovary are ranked seventh among malignant diseases of the female population and eighth among the causes of women's death from oncopathology in the world. About 240,000 new cases of malignant ovarian tumours are reported annually in the world and about 150,000 women die as a result of these diseases. The highest incidence of malignant ovarian tumours has been reported in low-income and developing countries. Thus, the highest rates are in North and Central/Eastern Europe, the average are in North America, Australia and Western Europe, and the lowest - in Asia and Africa [3].

In 2018 in Ukraine, according to the National Cancer Registry, ovarian malignancies accounted for $4.9 \%$ in the structure of the malignant neoplasms incidence of the female population, taking the 6th rank. The above pathology took 5 th place in the mortality structure and $6.5 \%$ accordingly [4].

According to the modern classification developed by experts of the World Health Organization, all ovarian tumours are divided into the following groups: epithelial tumours, mesenchymal tumours, mixed epithelial and mesenchymal tumours, sex cord-stromal tumours, mixed sex cord-stromal tumours, germ cell tumours, monodermal teratoma and somatic-type tumours arising from a dermoid cyst, germ cell-sex cord-stromal tumours, miscellaneous tumours, mesothelial tumours, soft tissue tumours, tumour-like lesion, lymphoid and myeloid tumours, secondary tumours [5].

In each case, the determination of the histological type of an ovarian tumour is based on an assessment of the tissue composition and its growth, the features of structural changes, signs of atypia, the presence and number of mitoses, as well as the characteristics of the cellular composition [6]. Unusual mosaic structure of the microscopic structure of ovarian neoplasms, diversity of their combinations, fuzzy boundaries between tumours of different degrees of maturity, abundance of metastatic lesions complicate the diagnostic process and, at times, create obstacles to the rational planning of therapeutic measures (the volume of surgical intervention and nature of conservative therapy), determining the prognosis of the course of the disease $[1,6]$.

The majority of ovarian tumours are of epithelial origin [7]. The ovarian Brenner tumour represents a rare epithelial ovarian neoplasm and accounts for $1-2 \%$ of all ovarian neoplasms [8]. Brenner tumours very rarely can occur in other locations, including the testis [9]. Identified in 1907 by a German pathologist Fritz Brenner, ovarian Brenner tumours are now subclassified into benign, borderline (atypical proliferative) and malignant categories [8]. The benign ones are the most frequent, representing about $95 \%$, the borderline represent about 4-5\%, and the malignant ones less than $1 \%$ [10]. Malignant Brenner tumour was firstly reported by von Numbers in 1945 [8]. In 1971 Roth and Sternberg reported borderline type of the ovarian Brenner tumour [11].

The issue of histogenesis of Brenner ovarian tumour is currently debatable. Historically proposed origins have included the ovarian surface epithelium, mesonephric remnants, rete ovarii, mucinous tumours, teratomas [12]. The most widely accepted hypothesis is that the tumour develops from Walthard cell nests, which are metaplastic transitional epithelium usually seen in the paratubal region [11]. It was noted that the transitional-like epithelium of Walthard cell nests is morphologically identical to the epithelial nests in Brenner tumours [12].

Given the rarity of the ovarian Brenner tumour, it seems relevant to analyze our own cases from practice in order to study its clinical and morphological features, which will contribute to a better understanding of this pathology and improve the diagnostic and treatment process.

\section{THE AIM}

The aim of the study is to identify clinical and morphological features of ovarian Brenner tumour.

\section{MATERIALS AND METHODS}

The material was 5 cases of Brenner ovarian tumour, diagnosed, taking into account modern morphological criteria [5], in the study of 4 cases of operational material and 1 case of autopsy observation for the period from 2007 to 2019.

The material was fixed in $10 \%$ neutral formalin. Tissue consolidation fixed in formalin was reached through alcohol of increased concentration, the Nikiforov liquid (96\% alcohol and diethyl ester in a 1:1 ratio), chloroform and filled in wax. Serial sections $4-5 \times 10^{-6} \mathrm{~m}$ thick were made from blocks for hematoxylin and eosin staining. In one case an immunohistochemical study was performed with monoclonal antibodies to cytokeratin 7,20 and vimentin. The microspecimens were examined on an Olympus BX-41 microscope (Japan).

\section{RESULTS AND DISCUSSION}

Diagnosis of a Brenner tumour using existing imaging methods is extremely difficult, and sometimes impossible. Considering the fact that the Brenner tumour of the ovary does not have specific signs, the results of ultrasound examination (fig. 1), computed tomography and magnetic resonance imaging only suggest the presence of the above tumour process in the patient. Pelvic organs are examined with a vaginal probe with frequency of 7-12 MHz, which allows you to visualize the structure of the uterus, endometrium and ovaries with high resolution.

For large tumours transabdominal scanning using a convex probe with a frequency of $3-5 \mathrm{MHz}$ is used. A tumour is more often of a solid structure, with fairly clear, slightly tuberous contours, sometimes a somewhat heterogeneous structure. Internal anechogenic inclusions corresponding to degenerative changes are often determined. A «stony» echostructure with the effect of lateral attenuation may occur. Sometimes a liquid component and calcifications may be present. The use of color Doppler mapping reveals single blood flow loci in the tumour structure. Elastography is not specific.

The main role in the diagnosis of Brenner ovarian tumour is assigned to morphological research methods. Microscopic examination of our own material in three cases revealed a 
benign variant of ovarian Brenner tumour. The latter was constructed from connective tissue, between the fibers of which it was determined the islets of various shapes and sizes, formed by polyhedral cells of epithelial nature, which often resembled a transitional epithelium of the urinary tract (fig. 2a, 2b). Some scientists note that the epithelial cells have a characteristic coffee bean nucleus with longitudinal grooves and pale cytoplasm [13]. In some places in the center of the islets we revealed round or round-oval cavities with pink homogeneous contents and desquamated cells (fig. $2 \mathrm{~b}$ ). In some fields of view between the connective tissue fibers, areas of dystrophic calcification and hyalinosis were noted.

Benign Brenner tumours are mainly asymptomatic and may have incidental findings particularly if small. In those symptomatic patients, the most common symptoms include abnormal vaginal bleeding, perceptible lumps and pain associated or not with the pelvic masses [14]. Infrequently, this neoplasm may manifest by Meigs syndrome, which includes a benign ovarian tumour, accompanied by ascites, hydrothorax and less often hydropericardium [15].

In our study a benign Brenner tumour was not diagnosed in three cases by clinicians and in the clinical diagnosis was documented as an ovarian cyst. Given the presence of multiple uterine leiomyoma in all of the above cases, these women underwent uterine extirpation (in one case with the cervix) with both appendages. This pathology was clinically manifested in all three cases by abdominal pain syndrome, which in one case was combined with bleeding from the uterine cavity.

The morphological study revealed a combination of a benign Brenner tumour with other pathologies of the ovary, uterus and cervix. Thus, the above pathology in one case combined with mucinous papillary cystadenoma of the ovary (fig. 3), endometriosis of the ovary (fig. 4), glandular-cystic endometrial hyperplasia, cervical nabothian cysts, in three cases with multiple uterine leiomyoma.

Other scientists noted also the combination of a benign Brenner tumour with various pathologies of the reproductive system organs. Brenner tumours coexist with other tumoural lesions, such as cystic mucinous tumour, serous cyst adenoma or the cystic dermoid teratoma in $25-36 \%$ of the cases. The presence of other tumoural or non-tumoural lesions in the female genital system would be due to the fact the Brenner tumours contain cells with a secretory function producing estrogenes, hormones that are responsible for the emergence of various lesions, from endometrial hyperplasia with vaginal bleeding to ovarian tumours [10]. Bleeding from the uterine cavity and morphologically diagnosed glandular-cystic endometrial hyperplasia noted by us can also possibly be a manifestation of the estrogenic effect of the Brenner tumour.

E. Kuhn et al. showed that luteinized stromal cells immediately adjacent to the epithelial nests of the Brenner tumours, as well as the epithelial nests themselves, are involved in androgen biosynthesis in view of the presence of AKR1C3, a key enzyme in the production of androgens, in these cells and that hormone stimulation therefore probably has a role in the development of Brenner tumours as the epithelial component contains androgen receptor [16]. The androgen-producing activity of a Brenner tumour may cause masculinization in patients [17].
In our study, in two cases, a Brenner malignant tumour was diagnosed morphologically, not detected or correctly interpreted by the attending physicians in patients.

In the first case, a woman had clinically determined abdominal pain, complaints of an increase in the size of the abdomen, a large ovarian cyst and multiple uterine leiomyoma were documented in the clinical diagnosis. This woman underwent surgery, during which the uterus with the cervix and both appendages, a fragment of the omentum were removed. The results of a morphological study of the surgical material revealed a combination of a malignant ovarian Brenner tumour with a serous ovarian cyst, uterine leiomyoma, cervical nabothian cysts. Morphologically, the tumour process was characterized by the presence of islets of squamous and transitional cancer separated by connective tissue layers. In some fields of view in the epithelial nests and islets we noted the structure of adeno-squamous cell carcinoma with the signs of mucus formation and the presence of signet-ring cells (fig. 5a, 5b). In the obtained omentum fragment, metastases of the ovarian Brenner malignant tumour were noted.

In the second case, a woman had a pronounced pain syndrome, signs of intoxication and small bowel obstruction. Cancer of the small intestine was documented in the clinical diagnosis. The woman died. An autopsy and the results of a histological examination of autopsy material revealed a malignant ovarian Brenner tumour with metastases in the omentum, small intestine (fig. 6), which has led to the development of intestinal obstruction, serous-fibrinous peritonitis and intoxication. The cause of death was the intoxication of combined genesis due to the presence of a malignant ovarian Brenner tumour and the development of small bowel obstruction with serous-fibrinous peritonitis. In this case a malignant ovarian Brenner tumour was combined with uterine leiomyoma, glandular-cystic endometrial hyperplasia. It was morphologically characterized by the presence of invasive nests and foci of neoplastic cells with pronounced proliferation and atypia, the structure of which in most fields of view corresponded to transitional cell carcinoma (fig. 7) and in some fields of view - squamous cell carcinoma. In some fields of view in the center of the nests were found the cavities filled with eosinophilic masses with desquamated cells.

Benign ovarian Brenner tumour, as shown by the analysis of our cases, has a fairly clear morphological picture. However, the nosological specification of a malignant ovarian Brenner tumour sometimes causes certain difficulties. A Brenner tumour is known to undergo both monomorphic and dimorphic differentiation during malignancy. The latter pathway leads to the formation of adeno-squamous cell carcinoma with the signs of intracellular mucus formation in the glandular component. Diagnosis of this variant of the Brenner tumour is not difficult. However, in cases of unilaterally developed monomorphic variants of this nosology, the complexity can be insurmountable. In these patients, the tumour has the structure of either purely squamous or transitional cell carcinoma. Then it is required to find the structures of the previous or coexisting benign Brenner tumour and establish transitions between the two processes [1]. In the studied cases of malignant ovarian Brenner tumours we revealed coexisting structures of a benign Brenner tumour.

Despite the fact that microscopic examination remains the first method in the diagnosis of ovarian Brenner tumours, in 


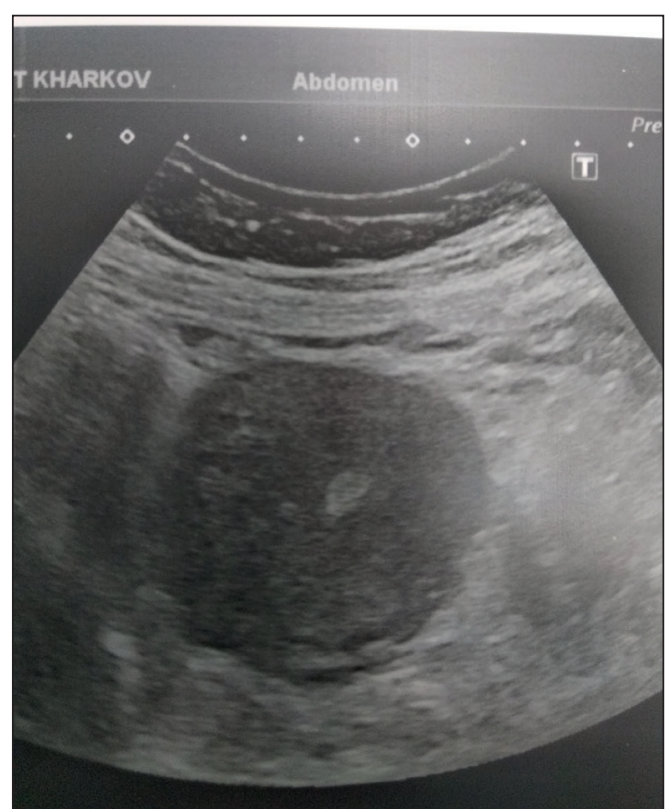

Fig. 1. Ultrasound investigation. Transabdominal scan. 3-5 MHz multifrequency convex sensor. A solid hypoechoic tumour is visualized in the right ovary of a somewhat heterogeneous echostructure with fairly clear tuberous contours, $8 \times 9 \mathrm{~cm}$ in size.
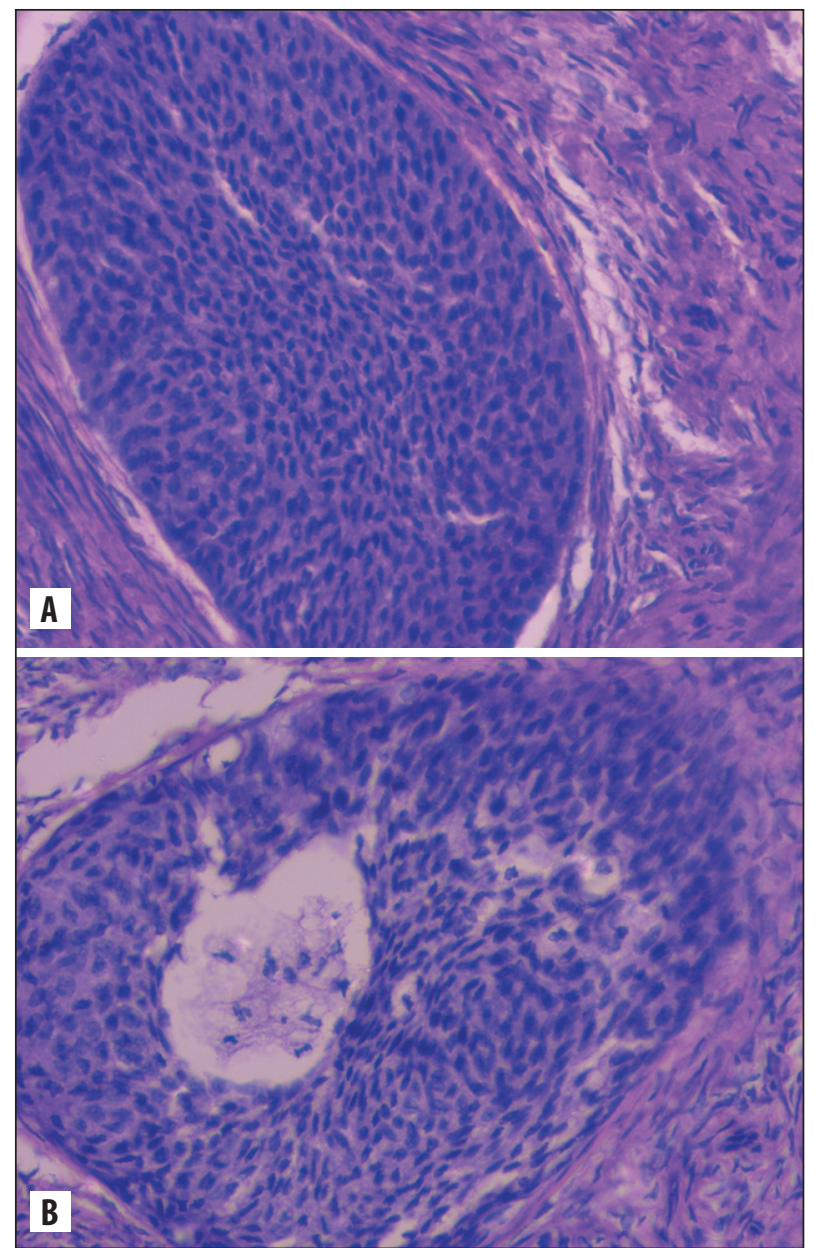

Fig. 2. There are the islets of epithelial cells resembling transitional epithelium $(a, b)$ in the benign ovarian Brenner tumour. Some islands are characterized by the presence of round-oval cavity filled with eosinophilic masses and desquamated cells (b). Stained with hematoxylin and eosin, $\times 100$.

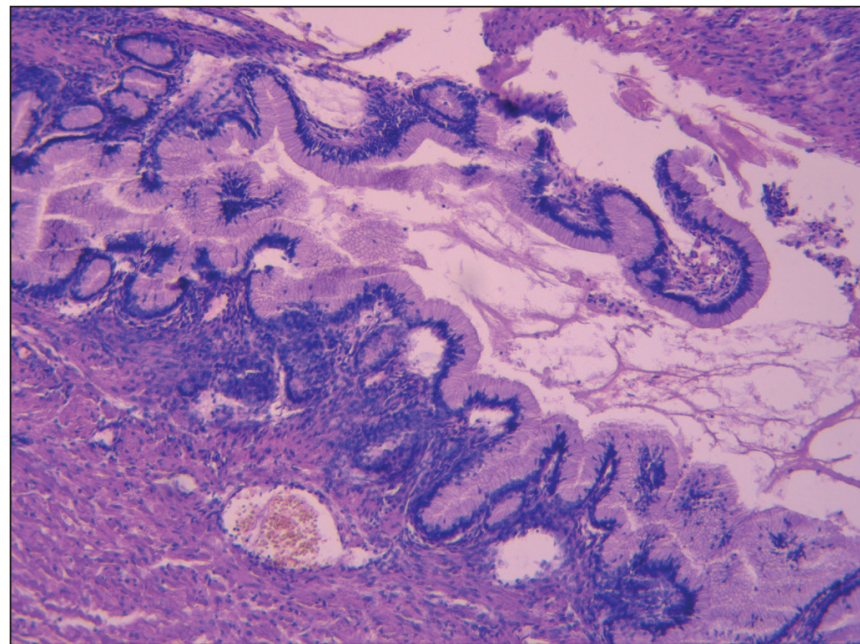

Fig. 3. Mucinous papillary cystadenoma of the ovary. Stained with hematoxylin and eosin, $\times 100$.

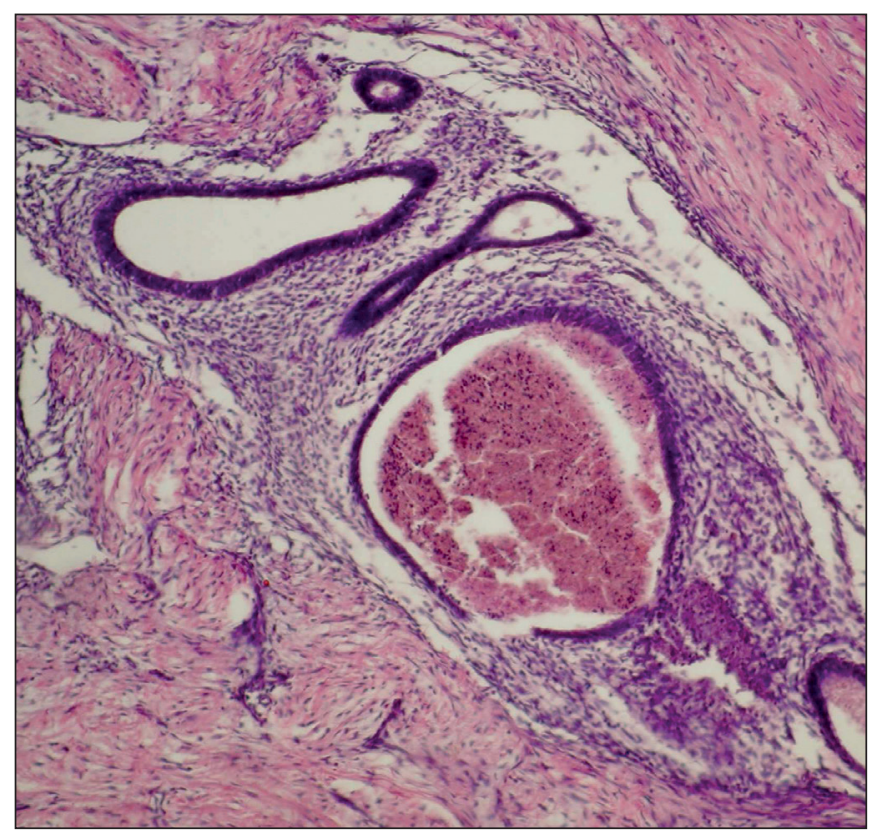

Fig. 4. Ovarian endometriosis. Stained with hematoxylin and eosin, $\times 100$.

some cases an immunohistochemical study is necessary to determine the exact histotype of the tumour [17]. Brenner tumours, including benign, borderline and malignant, express cytokeratin 7, p63, S100P, GATA3, uroplakin and thrombomodulin, but do not express, or only focally express, cytokeratin $20[5,18]$. The fibrous stroma of a Brenner tumour expresses vimentin [19].

In one case of a malignant ovarian Brenner tumour, a brief analysis of which was published earlier [20], during the morphological diagnosis using routine staining methods, difficulties arose in establishing the histogenetic origin of the tumour, which required an immunohistochemical study. Immunohistochemically it was detected the expression of cytokeratin 7 by the epithelial tumour cells (fig. 8), vimentin by the stromal cells (fig. 9), and a negative reaction with monoclonal antibody to cytokeratin 20 .

Molecular investigations have been carried out to explain the progression of the benign ovarian Brenner tumour to the atypical proliferative Brenner tumour, as well as the progression 

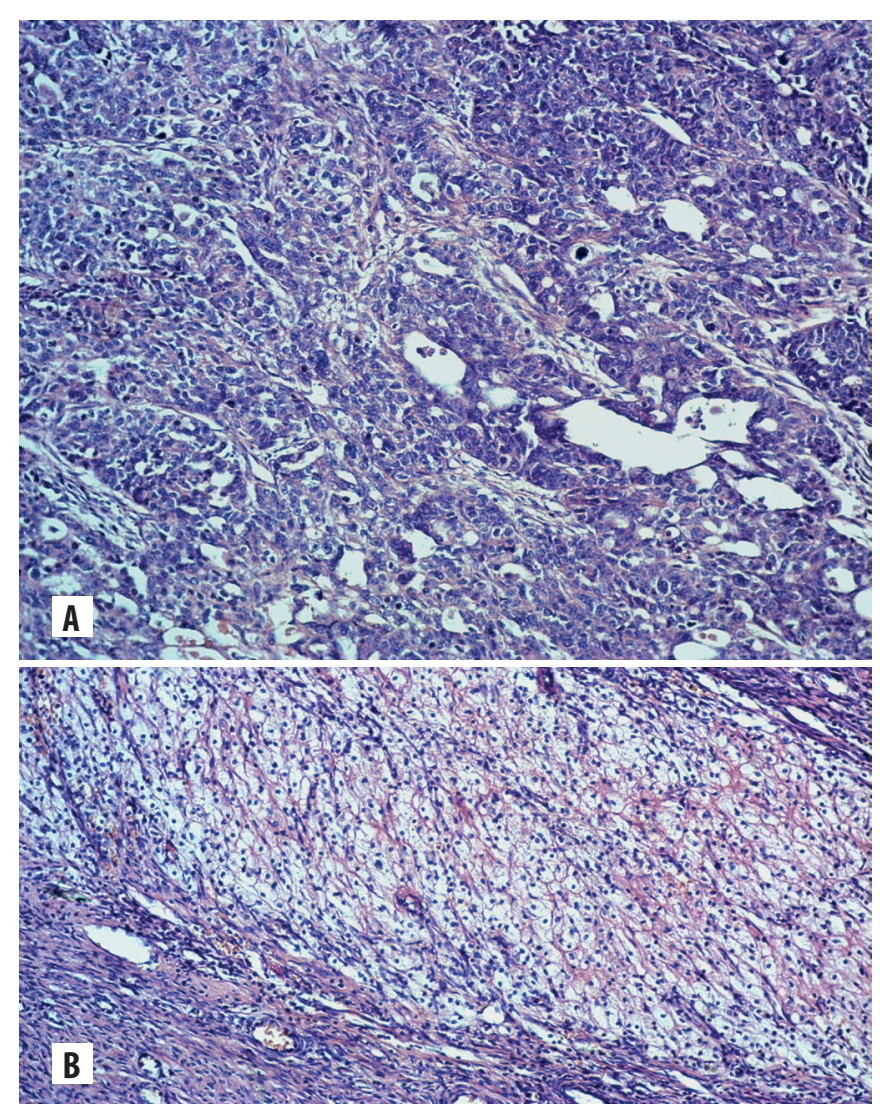

Fig. 5. In the epithelial nests and islets, the structure of adeno-squamous cell carcinoma (a) with the signs of mucus formation and the presence of signet-ring cells (b) is noted. Stained with hematoxylin and eosin, $\times 100$.

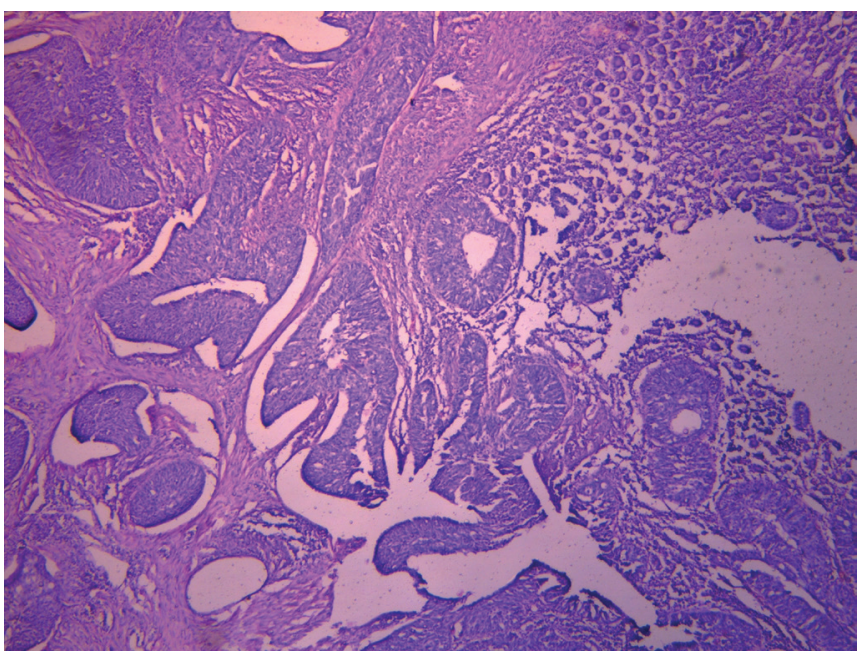

Fig. 6. Metastasis of a malignant ovarian Brenner tumour in the small intestine wall. Stained with hematoxylin and eosin, $\times 40$.

of the benign and atypical proliferative Brenner tumour to the malignant one [16].

A comparative analysis of the material showed that the connective tissue component was more pronounced in the benign Brenner tumour than the malignant variant, which was also noted by other scientists [17].

Malignant ovarian Brenner tumour compared with a benign variant is more often manifested by any symptoms. The clinical manifestations of malignant Brenner tumour are various. They in-

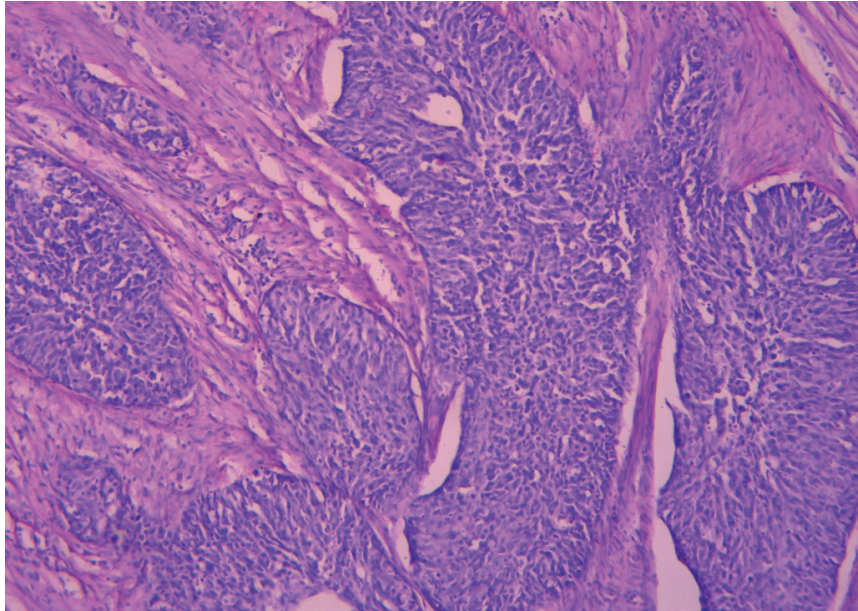

Fig. 7. Among connective tissue fibers, there are the invasive nests and foci of neoplastic cells with pronounced proliferation and atypia, the structure of which resembles transitional cell carcinoma. Stained with hematoxylin and eosin, $\times 100$.

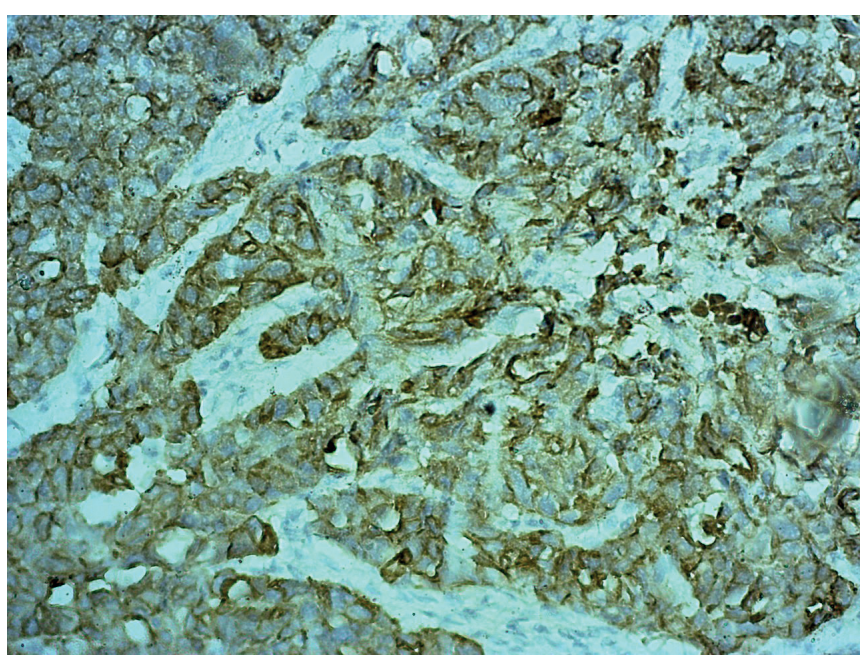

Fig. 8. Expression of cytokeratin 7 by the epithelial cells of a malignant ovarian Brenner tumour. Immunohistochemical reaction with monoclonal antibody to cytokeratin $7, \times 200$.

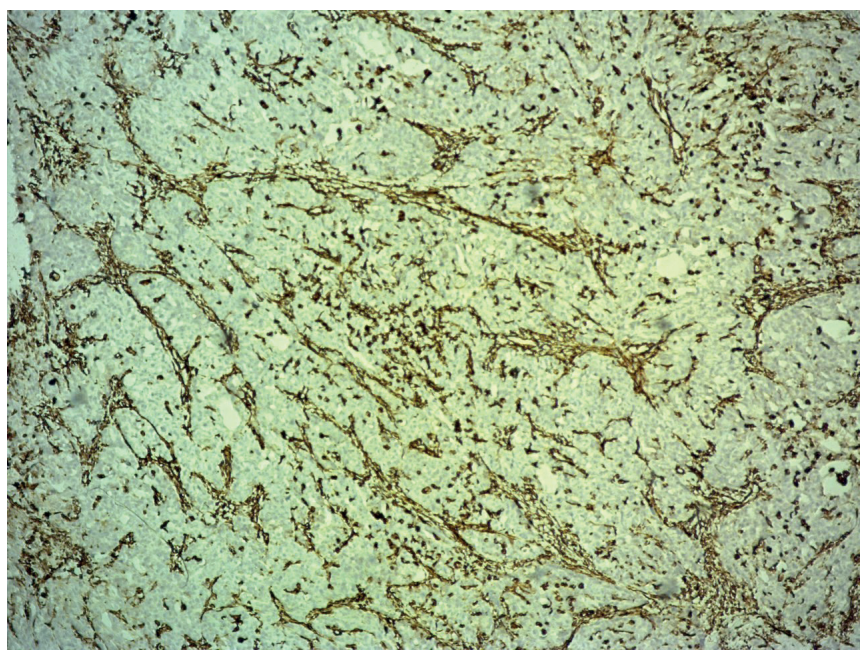

Fig. 9. Expression of vimentin by the connective tissue stroma of a malignant ovarian Brenner tumour. Immunohistochemical reaction with monoclonal antibody to vimentin, $\times 200$. 
clude abdominal pain, metrorrhagia, nausea, vomiting, back pain . Tumour-induced cachexia and weight loss can also be seen [11]

According to the literature data, malignant Brenner tumours metastasize so rare [21]. It was described that the malignant Brenner tumour can metastasize to the skin, lungs, central nervous system or shows tendency for intraperitoneal dissemination [15]. In our study in all cases a malignant ovarian Brenner tumour metastasized to the omentum, and in one case also to the small intestine wall.

In a macroscopic examination, in the case of a diagnosed benign variant, the tumour resembled a node with a diameter of 0.3 to $0.7 \mathrm{~cm}$ with dense consistency, round or round-oval in shape, in some places with small cysts with a diameter of 0.1 to $0.3 \mathrm{~cm}$ with mucus-like translucent contents. The size of the ovary in a benign Brenner tumour did not change or increased slightly. Macroscopically, a malignant Brenner tumour resulted in a pronounced ovarian enlargement in size and was represented by a node from 1.0 to $12.0 \mathrm{~cm}$ in diameter, whitish-gray or brown colour, dense or soft consistency, with cysts from 0.4 $\mathrm{cm}$ to $1.0 \mathrm{~cm}$ in diameter with whitish translucent or brown contents.

Significantly large sizes of the Brenner tumour in malignant variant compared with the benign variant were also identified by other scientists. Accordingly, it was noted that the size of Brenner tumours correlated with histologic grade: most benign tumours were, in general, $5-6 \mathrm{~cm}$ in diameter, occasionally exceeding $10 \mathrm{~cm}$. Borderline and malignant Brenner tumours can reach $30 \mathrm{~cm}$ [13].

A Brenner tumour, according to the literature, can have both unilateral and bilateral nature of the lesion. A more frequent involvement in the pathological process of the left ovary compared with the right was also found. Benign Brenner tumour, as a rule, has a one-sided nature of the lesion [22]. In malignant Brenner tumours bilateral lesions were found in 5-14\% of cases, in other cases it was unilateral lesions [23]. In our study, in all cases, Brenner tumour had a one-sided nature of the lesion. Its benign variant in all cases was detected in the left ovary and malignant - in the first case in the right ovary and in the second case in the left ovary.

The average age of patients with Brenner ovarian tumour was 51.8 years. With its malignant variant, the average age ( 55.8 years) of patients was higher compared with the average age (49.3 years) of patients with a benign variant. It has been noted by the scientists that Brenner tumours develop in premenopause or menopause women. Numerous studies have showed that the average age at which these tumours are diagnosed is 46-63 years. Benign Brenner tumours seem to develop also in women aged between 30 and 59 years, while malignant and borderline tumours develop in older women (45-60 years) [10] .

In this study, we did not find cases of a borderline variant of Brenner tumour. Borderline Brenner tumours compared to benign variant showed several large, irregular-shaped nests of tumour cells, most of which displayed cystic dilatation with intraluminal papillary or polypoid protrusions [24]. Borderline Brenner tumours have areas of atypia coexistent with benign components.

The cytologic findings that qualify a Brenner tumour as proliferative or borderline are as follows: mucinous or squa- mous metaplasia in transitional epithelium, complex glandular formation, nuclear atypia including hyperchromatic nuclei, coarse chromatin clumping, prominent nucleoli and increased mitotic activity. Focal areas resembling noninvasive papillary transitional carcinoma or papillary squamous carcinoma in situ have also been reported in borderline Brenner tumours. Some borderline tumours contain localized calcification [11].

Due to the rarity of ovarian Brenner tumor treatment strategy of patients with this pathology is not entirely clear. The main method is surgery. Issues related to radiation therapy and chemotherapy are still debatable and require further research. The prognosis of benign ovarian Brenner tumours is favorable. Borderline tumours do not metastasize, but can relapse. The prognosis of malignant ovarian Brenner tumours depends on the presence or absence of metastases and the prevalence of the tumour process $[5,17]$.

\section{CONCLUSIONS}

The analysis of own cases from practice of ovarian Brenner tumour has shown the following:

1. Ovarian Brenner tumour is a rather rare pathology, the histogenesis of which is debatable. Morphological examination is the main method for its diagnosing.

2. Ovarian Brenner tumours developed in women of middle and old age (the average age was 51.8 years). Women with a malignant ovarian Brenner tumour were older than women with a benign variant (the average age in women with a malignant variant was 55.8 years, with a benign variant -49.3 years). Benign ovarian Brenner tumour occurred more frequently compared with a malignant one. Malignant and benign variants of ovarian Brenner tumour were characterized by a one-sided nature of the lesion with frequent involvement in the pathological process of the left ovary. Clinically, in patients with a benign variant of the Brenner tumour in all cases an abdominal pain syndrome was determined, combined in one case with metrorrhagia. A malignant ovarian Brenner tumour was clinically manifested by severe abdominal pain syndrome, combined in one case with complaints of an increase in the size of the abdomen, and in another case with intoxication syndrome and a clinic of small bowel obstruction. In all cases a malignant ovarian Brenner tumour metastasized to the omentum and in one case also to the small intestine wall. 3. Macroscopically the ovarian Brenner tumour had the form of a node, the dimensions of which were significantly larger for the malignant variant compared with a benign, dense or soft consistency, on the cross section of a whitish-gray or brown color with cysts. A damaged ovary with a malignant variant of a Brenner tumour significantly increased in size, while with a benign one, its size did not change or increased slightly. In all cases the malignant and benign variants of ovarian Brenner tumour were combined with various reproductive system organs pathologies (mucinous papillary cystadenoma of the ovary, serous ovarian cyst, ovarian endometriosis, endometrial hyperplasia, cervical nabothian cysts, uterine leiomyoma). 


\section{REFERENCES}

1. Karseladze A.I. Nekotorye problemy klinicheskoj morfologii jepitelialnyh opuholej jaichnikov [Some problems of the clinical morphology of epithelial ovarian tumors]. Practical oncology. 2000;4:14-18. (Ru)

2. Sofi M.A., Bashir N., Afshan, Khajuria A., Ali N. Histopathological pattern of ovarian tumours - an experience. International journal of current research and review. 2018;10(9):15-21.

3. Svintsitsky V.S., Nespryadko S.V., Renkas O.P. Suchasni rekomendacii diagnostyky ta likuvannja epitelialnogo raku jajechnykiv [Current recommendations for the diagnosis and treatment of epithelial ovarian cancer]. Oncology. 2019;21(3):192-199. (Ua)

4. FedorenkoZ.P.,Michailovich Y.Yo., GoulakL.O., etal. Bulletin of national cancer registry of Ukraine «Cancer in Ukraine, 2018-2019». Kyiv; 2020.82 p.

5. Kurman R.J., Carcangiu M.L., Herrington C.S., Young R.H. WHO classification of tumours of female reproductive organs. Lyon: IARC Press; 2014. 307 p.

6. Bolgova L.S., Grabovoy A.N., Marinenko S.V., et al. Nekotorye aspekty izuchenija gistologicheskih tipov novoobrazovanij jaichnika [Some aspects of ovarian neoplasms histological types studying]. Clinical oncology. 2016;1(21):44-46. (Ru)

7. Farr R.N., Apostol R., Nezhat C., Pejovic T. New insights in the pathophysiology of ovarian cancer and implications for screening and prevention. American journal of obstetrics and gynecology. 2015;213(3):262-267.

8. Lang S.M., Mills A.M., Cantrell L. Malignant Brenner tumor of the ovary: review and case report. Gynecologic oncology reports. 2017;22:26-31.

9. Jodha B.S., Garg R. Brenner tumor of ovary: an incidental finding: a case report. International journal of reproduction, contraception, obstetrics and gynecology. 2017;6(3):1132-1135.

10. Albu D.F., Albu C.C., Gogănău A.M., et al. Borderline Brenner tumors associated with ovarian cyst - case presentation. Romanian journal of morphology and embryology. 2016;57(2):893-898.

11. Zheng R., HellerD.S. Borderline Brenner Tumor (a review of the literature). Archive of pathology and laboratory medicine. 2019;143:1278-1280.

12. Seidman J.D., Khedmati F. Exploring the histogenesis of ovarian mucinous and transitional cell (Brenner) neoplasms and their relationship with Walthard cell nests (a study of 120 tumors). Archive of pathology and laboratory medicine. 2008;132:1753-1760.

13. Weinberger V., Minár L., Felsinger M., et al. Brenner tumor of the ovary - ultrasound features and clinical management of a rare ovarian tumor mimicking ovarian cancer. Ginekologia Polska. 2018; 89(7):357-363.

14. YueZ., Si T., Pan Z., et al. Malignant Brenner tumor of the ovary: clinical, pathological and demographic analyses of 10 cases. International journal of clinical and experimental pathology. 2016;9(5):5642-5646.

15. Klasa L., Wydra D., Biernat W. Recurrence of Brenner ovary borderline tumor in the abdominal wall postoperative scar - a case report and research of the literature. Ginekologia Polska. 2014;11(85):873-876.

16. Kuhn E., Ayhan A., Shih le-M., et al. The pathogenesis of atypical proliferative Brenner tumor: an immunohistochemical and molecular genetic analysis. Modern Pathology. 2014;27:231-237.

17. Cherepanova E.V., Laktionov K.P., Anurova O.A., Zotikov A.I. Perehodnokletochnye opuholi jaichnikov [Transitional cell tumors of the ovary]. Tumors of female reproductive system. 2012;2:70-72. (Ru)

18. Hauptmann S., Friedrich K., Redline R., Avril S. Ovarian borderline tumors in the 2014WHO classification: evolving concepts and diagnostic criteria. Virchows Archiv. 2017; 470:125-142.
19. Tuffaha M., Gichka S., Guski H. Immunogistohimicheskaja diagnostika opuholej [Immunohistochemical diagnosis of tumors]. Kyev; 2013.223 p. $(\mathrm{Ru})$

20. Dyadyk 0.0., Nekrasova L.G., Zaryczka V.I., et al. Zlojakisna puhlyna Brennera: opys klinichnogo vypadku [Malignant Brenner tumor: a case report]. Morphologia. 2016;10(3):157-160. (Ua)

21. Borah T., Mahanta R.K., Bora B.D., Saikia S. Brenner tumor of ovary: an incidental finding. Journal of mid-life health. 2011;2(1):40-41.

22. Green G.E., Mortele K.J., Glickman J.N., Benson C.B. Brenner tumors of the ovary. Sonographic and computed tomographic imaging features. Journal of ultrasound in medicine. 2006;25:1245-1251.

23. Turgay B., Koyuncu K., Taşkin S., Ortaç U.F. Features of ovarian Brenner tumors: experience of s single tertiary center. Turkish journal of obstetrics and gynecology. 2017; 14:133-137.

24. Park C.K., Koh C.W., Yoon G., et al. Morphologic alterations of ovarian malignant Brenner tumors following chemotherapy. International journal of clinical and experimental pathology. 2016; 9(8):8102-8111.

\section{ORCID and contributionship:}

Mykhailo S. Myroshnychenko - 0000-0002-6920-8374 A,D,F

Olena O. Dyadyk - 0000-0002-9912-4286 ${ }^{B, E}$

Victor D. Urzhumov - 0000-0002-8648-7758 ${ }^{A, F}$

Nataliia V. Kapustnyk - 0000-0002-4875-398X ${ }^{A, B, D}$,

Iryna V. Borzenkova - 0000-0002-0701-5286 C,F

Larisa I. Selivanova - 0000-0001-6590-2601 C,D

Inna I. Torianyk - 0000-0001-6843-8808 ${ }^{A, E}$

Yuliia Ya. Fedulenkova - 0000-0001-8599-9500 A,E,F

Iuliia M. Kalashnyk - 0000-0002-7733-3503 ${ }^{E}$

Pavel V. Tkachenko - 0000-0002-7842-8117 B,E

Varvara R. Hryhorenko - 0000-0001-6923-5906 C,F

Dmytro V. Molodan - 0000-0002-7679-8288 ${ }^{B, E}$

Serhii S. Myroshnychenko - 0000-0003-4723-1490 ${ }^{E}$

\section{Conflict of interest:}

The Authors declare no conflict of interest.

\section{CORRESPONDING AUTHOR Mykhailo S. Myroshnychenko}

Kharkiv National Medical University, Pathological Anatomy Department str. Svetlaya27A, apt. 70, 61129, Kharkiv, Ukraine

tel: +380501699763, +380961033038

e-mail: msmyroshnychenko@ukr.net

Received: 11.03 .2020

Accepted: 19.06 .2020

A - Work concept and design, B - Data collection and analysis, C - Responsibility for statistical analysis, D-Writing the article, $\mathbf{E}$-Critical review, F- Final approval of the article 